九州大学学術情報リポジトリ

Kyushu University Institutional Repository

\title{
The Effectiveness of Jet Impingement Cooling System on Various Flat Plate Surface
}

Aiman. Y.

School of Mechanical Engineering, Faculty of Engineering, Universiti Teknologi Malaysia

M. Firdaus

School of Mechanical Engineering, Faculty of Engineering, Universiti Teknologi Malaysia

M. N. Musa

School of Mechanical Engineering, Faculty of Engineering, Universiti Teknologi Malaysia

S. Syahrullail

School of Mechanical Engineering, Faculty of Engineering, Universiti Teknologi Malaysia

https://doi.org/10.5109/4372277

出版情報：Evergreen. 8 (1)，pp.187-192，2021-03. 九州大学グリーンテクノロジー研究教育センター バージョン：

権利関係 : 


\title{
The Effectiveness of Jet Impingement Cooling System on Various Flat Plate Surface
}

\author{
Aiman.Y, M.Firdaus, M.N. Musa, S. Syahrullail \\ ${ }^{1}$ School of Mechanical Engineering, Faculty of Engineering, Universiti Teknologi Malaysia, 81310 UTM \\ Skudai, Johor, Malaysia
}

*Corresponding Author’s email: wmaiman91@gmail.com/syahruls@mail.fkm.utm.my

(Received November 27, 2020; Revised February 19, 2021; accepted March 23, 2021).

\begin{abstract}
This manuscript present investigation the effectiveness of jet impingement cooling system on flat plate surface. Jet impingement can give high heat flux cooling effect. This type of cooling system is very useful as it may be used in a lot of machine and instruments such as piston, supercomputer, microchip, food technology and hybrid car electronic circuit. This project have three main objectives that need to achieve. Firstly, this project can determine the best distance from nozzle to plate surface and then determine the dimensionless ratio between distance from nozzle to plate surface and the diameter of circular nozzle. Next is this project can observe the best mass blow rate, ranging from laminar flow to turbulent flow. The purpose to having two types of flows is to check which flow can give the best cooling effect. Lastly, by choosing three type of materials that have different surface roughness is to study the effect of surface roughness and cooling effect. From the experiment, higher surface roughness does not give the best cooling effect while smoother surface roughness give the better results. However, just like mass blow rate, it has it range on where the best cooling effect can be achieved. If the difference between surface temperature and isothermal temperature is too high, it will be a drawback to the cooling system. For the final result, the best jet impingement cooling system can be obtained at dimensionless $\mathrm{s} / \mathrm{d}=10$ at mass blow rate equal to $8.4 \mathrm{~m} / \mathrm{s}$ using zinc plate.
\end{abstract}

Keywords: Jet impingement; Fluid Mechanic; Heat transfer; Laminar flow

\section{Introduction and background}

Jet impingement is a method of cooling which is using fluid as its medium, either liquid or gas that has high velocity issuing from a nozzle to a target surface. Jet impingement is a convection type of heat transfer and can be considered as an effective method to cool surface because it enhances the local heat transfer performance. There are many research based on jet impingement being done until this date ${ }^{1)}$ Jet impingement cooling system is a promising cooling mechanism that has an effective heat and mass transfer performance. However, none of the studies were made that focusing on the type of surface roughness ${ }^{2)}$ Among the factors that has been considered are type of nozzle, nozzle to surface distance, Reynolds number and shape of the target surface that will determine effectiveness of jet impingement on surface ${ }^{3)}$

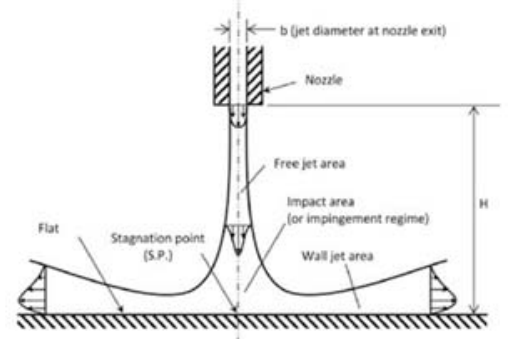

Fig. 1: Jet impingement schematic diagram
Most of the early research focuses on effect of smooth flat surface using jet impingement. From the previous research that done by Jung et al., ${ }^{4)}$, a lot of researches concentrate on the Reynolds number jet on heat transfer efficiency and nozzle to surface distance. Besides that, Lee et al., ${ }^{5)}$ also have done the research of the heat transfer characteristic with an air issuing from an elliptical nozzle and from a long straight pipe nozzle. As a result, they claimed that in the fully formed area, the decreases of the het centreline velocity is correlate to the inverse of distance, these situation will lead to the rise of turbulence level in approaching jet flow due to the stronger exchange of momentum together at surrounding ambient air.

Besides the efficiency of flat surface output, many studies has concentrate on curve surface due to its significance and use in industry. Investigation of local and average heat flow with a sequence of circular jets impinging on a concave surface has been study by Modak et al., 6), and from the research, it is found that the heat transfer on concave surface is $20 \%$ higher than flat surface. This result has agreed by Thoman ${ }^{7}$. Another research is done by Hrycak ${ }^{8}$ addressed that the local heat transfer at a stagnation point on a concave surface higher than a flat surface due to its greater surface area, particularly for a shorter distance between the nozzle and the impenetrable surface. 
The nonlinear flow for slot-jet impinging heat transfer characteristics over slightly curved surfaces that used a rectangular slot for the geometry of the nozzle and assumed a steady heat flux for the boundary surface state as studied by Guan et al. ${ }^{9}$. Two slightly curved surface geometries of concave and convex surfaces are used as goal surfaces. The geometry of the nozzle is a rectangular slot and the dimensionless distance between the nozzle and the surface is equal to $L / d=8$. Measurements are made for the Reynolds jet amount of turbulent flow for all curved surfaces. Correlations suggest that the impinging cooling rate is higher with the concave surface and increases with the increasing number of Reynolds

Recently, $\mathrm{Bu}$ et al. ${ }^{10)}$ performed an experimental analysis of jet impingement heat transfer on a variablecurvature concave surface in the wing leading edge. Experiments were performed over a wide variety of criteria, including the jet Reynolds number that is starting with 51020 until $85340,1.736$ to 19.76 for the $\mathrm{H} / \mathrm{d}$ (relative tube-to-surface distance), for angle circumferential $\theta$ is starting from $-60^{\circ}$ to $60^{\circ}$ of the jet holes on the piccolo tube. The aligned jet holes were investigated with single one, 2 and 3 row correspond to the jet impingement. It is found that the efficiency of the jet impingement heat transfer was improved by increasing the number of Reynolds ${ }^{16)}$.

The focus of this research is for the case of jet impinging of using three types of material with different surface roughness while using a nozzle of $6 \mathrm{~mm}$ diameter. The jet, in stagnant surrounding has the critical Reynolds number of 3000 of which the flow will become turbulent. In this experiment, the value of Vjet mention earlier is in between $4.5 \mathrm{~m} / \mathrm{s}$ up to $12.8 \mathrm{~m} / \mathrm{s}$ and Reynolds number is in between 1728.55 up to 4916.77 . These value was chosen based on the reference by N. Souris and H. Liakos 11) with an added value of 4916.77 to determine the maximum heat transfer will occur at turbulent flow. As for the surface roughness, the materials was selected randomly from the industrial usage that are aluminium, zinc and mild steel. The range of the surface roughness, $\varepsilon$ is in between 0.528 to $0.919 \mu \mathrm{m}$.

\section{Analysis and experimental setup}

\subsection{Fluid Mechanic}

There are several parameters of analysing the flow. However the primary parameter relating to the viscous behaviour of Newtonian fluids is the dimensionless Reynolds number.

$$
R e=\frac{\rho V L}{\mu}=\frac{V L}{v}=\frac{\rho V D}{\mu}
$$

Where:

V: Velocity

L: Length

D: Diameter

v: Kinematic viscosity $\mu$ : Dynamic viscosity

$\rho$ : Density of fluid

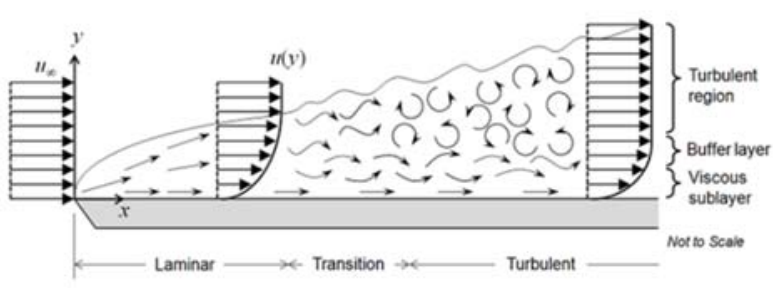

Fig. 2: Boundary layer diagram

For a laminar type of flow, the Reynolds number is $\leq$ 3000 for flow in tubes based on Petukhov equation. The flow is fully developed if the tube is sufficiently long in relative to the entry length and only then the entrance effect can be neglected. Laminar flow occurs when fluid flows in parallel layer, with no mixing between the layers. The fastest flow of this flow happens at the middle part of the pipe. This type of flow only encountered when highly viscous fluids flow in small diameter pipes or narrow passages ${ }^{12,15)}$. One of the example is when oil flow through the small size pipe.

Transitional flow as it name suggest, is a type of flow that is in between turbulent and laminar flow. Transition of flow from laminar to turbulent is caused by free-stream perturbations. In transitional flow, the flow can be either laminar or turbulent as it switches in disorderly fashion. As laminar flow $R e$ is $\leq 3000$, transitional Re is higher than 3000 and lower than 4000 in most cases. However, transitional flow Re can as high as 10000 in some cases where it only considered fully turbulent when Re reach higher value than 10000 .

Turbulent flow can be characterized by the irregular movement of particles in the fluid or it is known as chaotic behaviour. Turbulent flow contrast to laminar flow as the fluid does not flow in parallel layers, where the lateral mixing is very high, and there is an interference between the layers. In turbulent flow, speed of the fluid in the flow continuously undergoing changes at every point in term of magnitude and direction. As mentioned above, most of the cases turbulent flow will occur at Re more than 3000 and while it is known that flow will become fully turbulent when $\operatorname{Re}$ is greater than $10000^{13,22)}$.

\subsection{Method}

In this research, experimental study was conducted to determine the effectiveness of jet impingement system of flat plate surface with different materials. The parameters considered during the experiment setup are,

(a) Mass blowing jet

(b) Distance of nozzle from the surface, $\mathrm{s} / \mathrm{d}$

(c) Surface roughness

From the Fig. 3, the setup need to exact and consistent for each run as we seek for accuracy. The absent of one of 
the apparatus might not accepted as the parameters has been changed. The setup is designed to allow the determination of effectiveness of jet impinging for the heated flat plate surface in which the jet or air impingement came from the nozzle. The air was supplied by the large capacity tank pressurized by automatic shutoff air compressor.

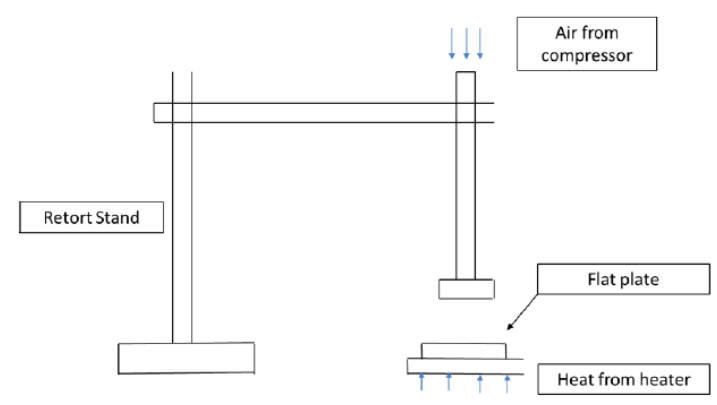

Fig. 3: Schematic diagram of experiment apparatus set up

Firstly the nozzle is attached to the retort stand and turn on the compressor. For starting test, set s/d at 5, four thermocouple attached to the heated flat plate surface as shown in Fig. 4 and one of thermocouple is attached at heat source. Connect Pico device to laptop, picolog software is open to monitor data of thermocouple, then use anemometer to detect speed of the jet, adjust the speed of jet until it reach desired speed using pressure regulator. Heat the plate until heat source at isothermal temperature of $100^{\circ} \mathrm{C}$. Record the temperature reading using Picolog device for about 20 seconds.

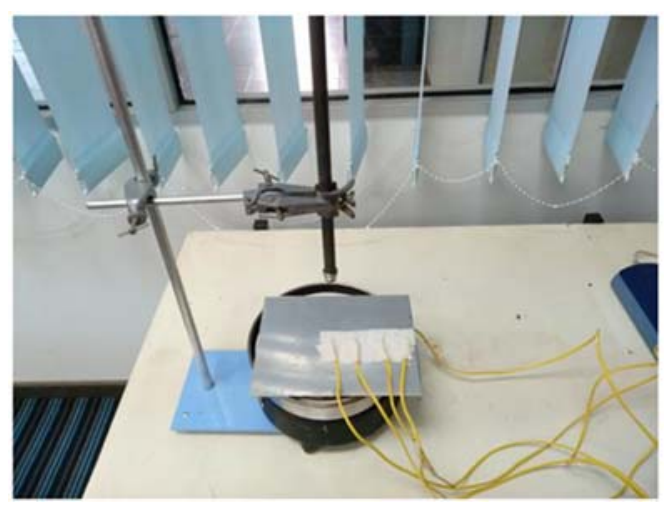

Fig. 4: Position of thermocouple

\section{Results and Discussion}

All the data obtained will be used to calculate the heat transfer coefficient, $h$ and then used for Nusselt number, $\mathrm{Nu}$ calculation ${ }^{18,19)}$. The calculated $\mathrm{Nu}$ and $\mathrm{h}$ value then is tabulated into a single table and plotted into several graphs. Overall, this experiments involved at least 27 case of experiments using 3 different models or materials that mentioned before that are aluminium, zinc and mild steel. Focus of the studies made are to get the best distance of nozzle to plate, jet velocity for cooling and material for cooling purpose.

\subsection{Surface Roughness}

Surface roughness test is need to be done as the materials used are different. Here it shows the difference of the materials in term of surface roughness. As mentioned in the table below, the standard of the experiment is using ISO 1997 using Surface Roughness Tester SJ310. The total reading taken for each material is three times and their average surface roughness then can be calculated.

Table 1. Average surface roughness

\begin{tabular}{lcc}
\hline Material & $\begin{array}{c}\text { Average } \\
\text { Surface } \\
\text { Roughness } \\
(\boldsymbol{\mu m})\end{array}$ & Standard \\
\hline Zinc & 0.633 & ISO 1997 \\
\hline Aluminium & 0.528 & \\
\hline Mild steel & 0.919 & \\
\hline
\end{tabular}

\subsection{Effect of temperature on s/d}

Result show the graph plotted that are Nusselt number vs position of thermocouple, temperature vs position of thermocouple and heat transfer coefficient vs position of thermocouple. Based on initial hypothesis, the average temperature is the lowest at $\mathrm{s} / \mathrm{d}=10$ for all cases. From there, graph will be plotted to monitor their behaviors and trends. First experiment case is for laminar flow when the air velocity is equal to $4.5 \mathrm{~m} / \mathrm{s}$. To observe the trend, only stagnation point data is plotted as it is the most critical point.

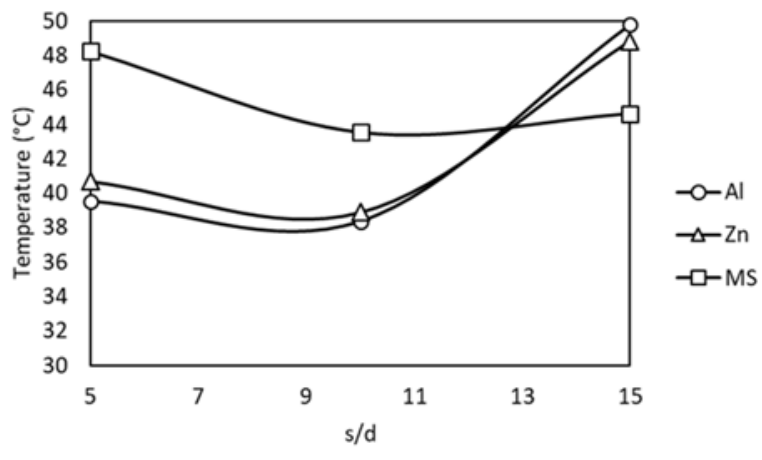

Fig. 5: $\mathrm{T}$ vs $\mathrm{s} / \mathrm{d}$ at $\mathrm{v}=4.5 \mathrm{~m} / \mathrm{s}$

Based on the Fig. 5, mild steel has highest temperature at $\mathrm{s} / \mathrm{d}=5$ while zinc and aluminium temperature are almost identical to each other. The same trend follow when $\mathrm{s} / \mathrm{d}=10$ but this time all of materials temperature dropped slightly and still zinc has the lowest temperature. At $\mathrm{s} / \mathrm{d}=15$ mild steel recorded lowest temperature but the value is still higher than its value when $\mathrm{s} / \mathrm{d}=10$. 


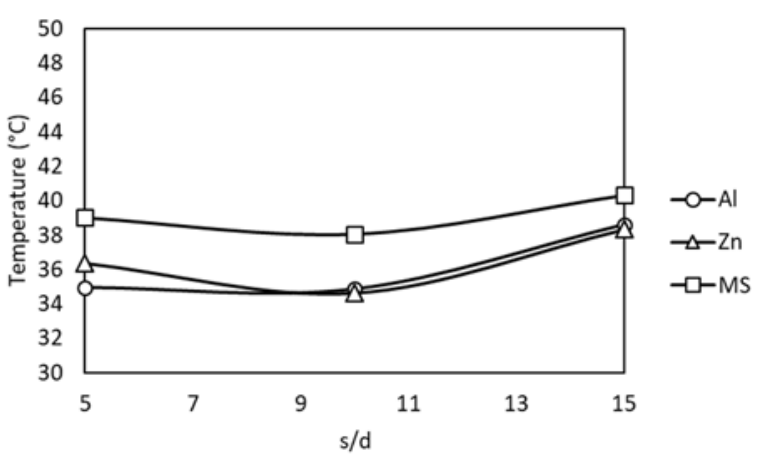

Fig. 6: $\mathrm{T}$ vs $\mathrm{s} / \mathrm{d}$ at $\mathrm{v}=8.4 \mathrm{~m} / \mathrm{s}$

Fig. 6 shows experiment case where the air velocity is $8.4 \mathrm{~m} / \mathrm{s}$. The Reynold number for this air velocity is 3169.81 that is well in the region of turbulent flow. As mentioned earlier, turbulent flow Reynold number started at 3000 for flow in pipe case. From the data, lowest temperature across surface are recorded at this condition for all materials. Mild steel has the highest temperature at all conditions of $\mathrm{s} / \mathrm{d}$. Zinc and aluminium are just like previous case, maintaining the gap of temperature between them closer than and lower than mild steel temperature. At s/d $=5$, lowest temperature is $34.97^{\circ} \mathrm{C}$ clocked by aluminium. However, zinc has recorded the lowest temperature from all experiment that is $34.63{ }^{\circ} \mathrm{C}$, which is recorded at $\mathrm{s} / \mathrm{d}=10$ that is slightly below the temperature of aluminium at $34.88^{\circ} \mathrm{C}$.

In Fig. 7 shows that the characteristic of the temperature of all plate surface with different $\mathrm{s} / \mathrm{d}$ at condition of $12.8 \mathrm{~m} / \mathrm{s}$. The Reynold number also indicate this condition is in the turbulent region. This is the third case and condition for the experiment. This condition is choose to determine whether the higher air velocity will enhance the effectiveness of jet impingement cooling system. Observation from the result, aluminium has the lowest temperature for all condition of $\mathrm{s} / \mathrm{d}$. The temperature at other point of thermocouple also has similar characteristic for this particular case. Aluminium has the lowest temperature at $35.41^{\circ} \mathrm{C}$ which is well below zinc at $36.34^{\circ} \mathrm{C}$ on this case. The temperature is recorded at $\mathrm{s} / \mathrm{d}=10$ which proves the lowest temperature can be obtained at this condition even when experimented using different air velocity.

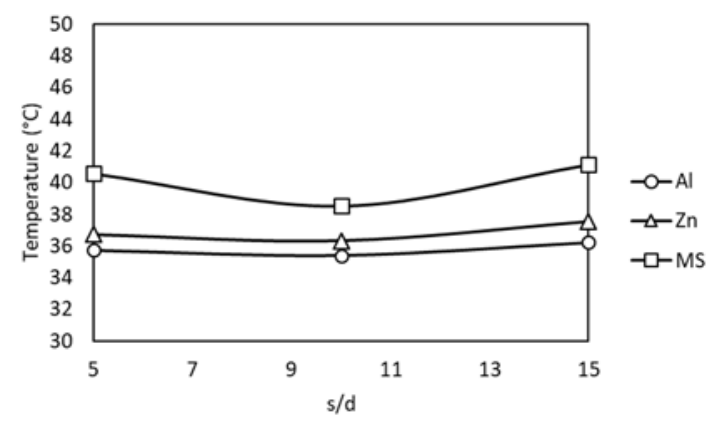

Fig. 7: $\mathrm{T}$ vs $\mathrm{s} / \mathrm{d}$ at $\mathrm{v}=12.8 \mathrm{~m} / \mathrm{s}$

\subsection{Effect of Heat Transfer coefficient on s/d}

The result of heat transfer coefficient, $h$ will be plotted against dimensionless $\mathrm{s} / \mathrm{d}$. Heat transfer coefficient is also being used to calculate other parameter as in this experiment, to calculate the value of Nusselt number. Heat transfer coefficient is the proportionality constant between the heat flux and temperature difference. First graph is plotted based on calculation made from Fig. 8. All of the plotted data is based on the stagnation point value. From the result obtain, it is proven that the relationship between heat transfer coefficient, $h$ and temperature is inversely proportional. As observed, s/d at 10 will give the highest value of heat transfer coefficient across all materials. Average highest value is coming from zinc where it has the highest value at $\mathrm{s} / \mathrm{d}=5$ and 10 . However, the highest $h$ value at $s / d=15$ is the value of mild steel. This could indicate that mild steel is the most suitable material for higher dimensionless $\mathrm{s} / \mathrm{d}$ value at laminar flow.

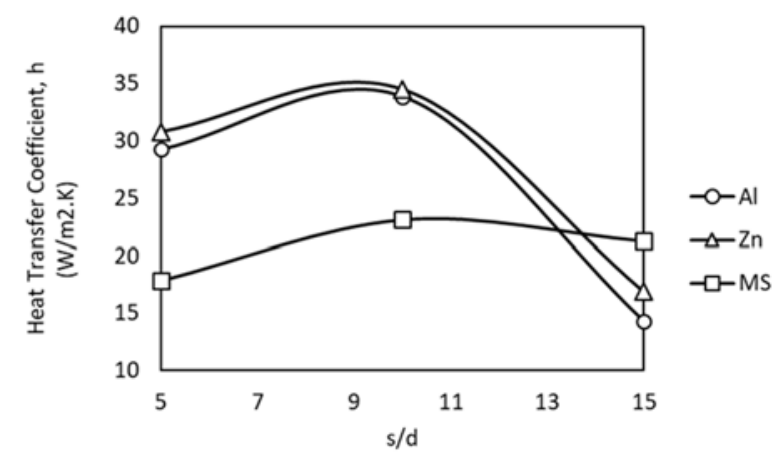

Fig. 8: h vs s/d at v $=4.5 \mathrm{~m} / \mathrm{s}$

From Figure 9, at s/d $=5$ aluminium has the highest value of $\mathrm{h}$ where it topple zinc at $48.1110 \mathrm{~W} / \mathrm{m} 2 . \mathrm{K}$. At s/d $=10$ the scenario change as zinc has overtaken the highest value for this condition and $\mathrm{s} / \mathrm{d}=15$ as well. Mild steel still has the lowest value of $h$ among the materials used, similar as for $4.5 \mathrm{~m} / \mathrm{s}$ case. This consistent trend could prove that mild steel is unsuitable material for jet impingement cooling in the condition of turbulent flow ${ }^{20-}$ ${ }^{21)}$. Highest value of $h$ is calculated in this case, larger than in the case of $4.5 \mathrm{~m} / \mathrm{s}$ and $12.8 \mathrm{~m} / \mathrm{s}$.

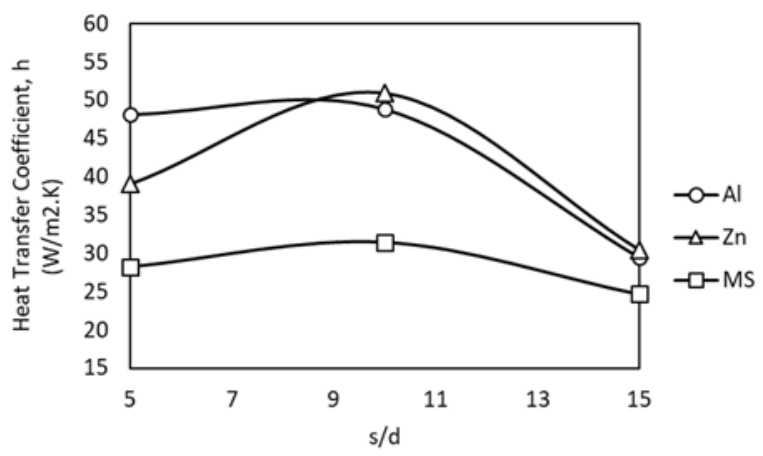

Fig. 9: $\mathrm{h}$ vs s/d at $v=8.4 \mathrm{~m} / \mathrm{s}$ 
For the $12.8 \mathrm{~m} / \mathrm{s}$ as shown in Fig. 10 the value of $\mathrm{h}$ is still not the highest among all three cases. This is caused by the temperature difference between plate surface and isothermal temperature of the heat source and between plate surface temperature and ambient temperature. At $12.8 \mathrm{~m} / \mathrm{s}$, overall highest value of $\mathrm{h}$ coming from aluminium. Only at $\mathrm{s} / \mathrm{d}=15$, zinc replaced aluminium for the highest value. Continuing the trend of other graphs before, mild steel has the lowest value of $h$ among the materials of plate surface

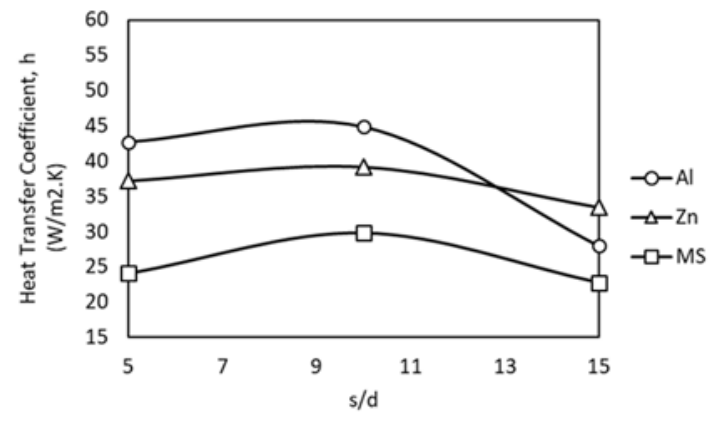

Fig. 10: $h$ vs $s / d$ at $v=12.8 \mathrm{~m} / \mathrm{s}$

\subsection{Effect of Nusselt Number on s/d}

Highest Nusselt number indicate the most effective jet impingement condition for this type of cooling system ${ }^{14}$, 17). As the calculated data shown most of the highest Nusselt number can be obtained at air velocity of $8.4 \mathrm{~m} / \mathrm{s}$, Fig. 11 will show the comparison of Nusselt number versus $\mathrm{s} / \mathrm{d}$ at $8.4 \mathrm{~m} / \mathrm{s}$ to get clearer view on comparison on different material. From the result also highest value of $\mathrm{Nu}$ is at $\mathrm{s} / \mathrm{d}=10$ which is the value of zinc. Based on overall pattern, most of the Nusselt number of zinc is higher than aluminium and mild steel although at some conditions the aluminium and mild steel has higher value. This proves that zinc can be used as material for all type of flow, also showing its flexibility on different dimensionless $\mathrm{s} / \mathrm{d}$.

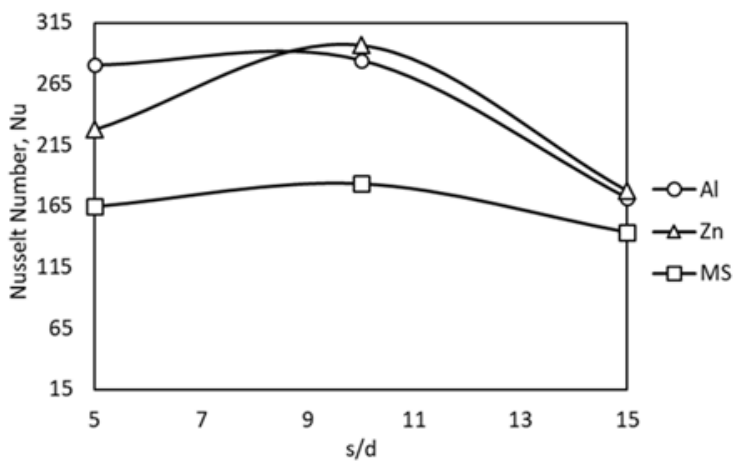

Fig. 11: Best $\mathrm{Nu}$ vs s/d

\section{Conclusions}

Based on the experiment that has been carried out, the effectiveness of jet impingement cooling system can be determined using several parameters. As per scope of studies, the type of nozzle used are circular nozzle with 6 $\mathrm{mm}$ diameter. The impingement has the highest value at stagnation point from all cases that has been studied. This may be attributed to a thinning of boundary layer caused by surface curvature and generation of Taylor-Gotler vertices that increase the rate of heat transfer.

When observing the temperature across materials, aluminium has the lowest average temperature among the materials which lead to early hypothesis that is has the highest Nusselt number and heat transfer coefficient. However, when calculating the heat transfer coefficient, the difference between plate surface temperature and surrounding are being considered. The isothermal temperature also has its parts in determining the heat transfer coefficient. As the relationship of Nusselt number and heat transfer coefficient is proportional, Nusselt number will increase if heat transfer coefficient increase. Highest Nusselt number value will indicate the most effective jet impingement cooling system.

\section{Acknowledgements}

The authors would like to express their thanks to the RMC of UTM for the Research Grant, GUP (17H96,15J28,20H29,FR 21H50), TDR Grant (05G23), FRGS Grant (5F074,5F173), School of Mechanical Engineering, UTM and Ministry of Higher Education for their support.

\section{References}

1) Henry, M. A., Reid, K. E., Bhavnani, S. H., Knight, R. W., Maddox, J. F., \& Brannon, W. D. (2018, May). Staggered and In-line Submerged Jet Arrays for Power Electronics Using Variable Area Discharge Manifolds: Part I-Experimental. In 2018 17th IEEE Intersociety Conference on Thermal and Thermomechanical Phenomena in Electronic Systems (ITherm) (pp. 410-416). IEEE.

2) Kwon, B., Foulkes, T., Yang, T., Miljkovic, N., \& King, W. P. (2019, May). Additively Manufactured Impinging Air Jet Cooler for High-Power Electronic Devices. In 2019 18th IEEE Intersociety Conference on Thermal and Thermomechanical Phenomena in Electronic Systems (ITherm) (pp. 941-945). IEEE.

3) Singh, D., Premachandran, B., \& Kohli, S. (2017). Double circular air jet impingement cooling of a heated circular cylinder. International Journal of Heat and Mass Transfer, 109, 619-646.

4) Jung, E. Y., Park, C. U., Lee, D. H., Kim, K. M., \& Cho, H. H. (2018). Effect of the injection angle on local heat transfer in a showerhead cooling with array impingement jets. International Journal of Thermal Sciences, 124, 344-355

5) Lee, D. H., Chung, Y. S., \& Kim, D. S. (1997). Turbulent flow and heat transfer measurements on a curved surface with a fully developed round impinging jet. International Journal of Heat and Fluid 
Flow, 18(1), 160-169.

6) Modak, M., Garg, K., Srinivasan, S., \& Sahu, S. K. (2017). Theoretical and experimental study on heat transfer characteristics of normally impinging two dimensional jets on a hot surface. International Journal of Thermal Sciences, 112, 174-187.

7) Thomann, H. (1968). Effect of streamwise wall curvature on heat transfer in a turbulent boundary layer. Journal of Fluid Mechanics, 33(2), 283-292.

8) Hrycak, P. (1983). Heat transfer from round impinging jets to a flat plate. International Journal of Heat and Mass Transfer, 26(12), 1857-1865.

9) Guan, T., Zhang, J. Z., Shan, Y., \& Hang, J. (2017). Conjugate heat transfer on leading edge of a conical wall subjected to external cold flow and internal hot jet impingement from chevron nozzle-Part 1: Experimental analysis. International Journal of Heat and Mass Transfer, 106, 329-338.

10) Bu, X., Peng, L., Lin, G., Bai, L., \& Wen, D. (2016). Jet impingement heat transfer on a concave surface in a wing leading edge: Experimental study and correlation development. Experimental Thermal and Fluid Science, 78, 199-207.

11) Souris, N. , Liakos, H. and Founti, M. (2004), Impinging jet cooling on concave surfaces. AIChE J., 50: 1672-1683. doi:10.1002/aic.10171

12) Ling, Y., Fuster, D., Tryggvason, G., \& Zaleski, S. (2019). A two-phase mixing layer between parallel gas and liquid streams: multiphase turbulence statistics and influence of interfacial instability. Journal of Fluid Mechanics, 859, 268-307.

13) Schlichting, H., \& Gersten, K. (2016). Boundarylayer theory. Springer.

14) Wittig, K., Nikrityuk, P., \& Richter, A. (2017). Drag coefficient and Nusselt number for porous particles under laminar flow conditions. International Journal of Heat and Mass Transfer, 112, 1005-1016.

15) Yinn, W. K., Kamar, H. M., Kamsah, N., \& Norazam, A. S. (2019). Effects of surgical staff turning motion on airflow distribution inside a hospital operating room. Evergreen

16) Yaningsih, I., Mahmood, M. H., Wijayanta, A. T., Miyazaki, T., \& Koyama, S. (2018). Experimental Study on Dehumidification Technology using Honeycomb Desiccant Block (Doctoral dissertation, Institute of Carbon-Neutral Energy Research (I2CNER), Kyushu University). Evergreen

17) Takeyeldein, M. M. (2019). Wind Turbine Design Using Thin Airfoil SD2030 (Doctoral dissertation, Kyushu University). Evergreen

18) Ko, J., Takata, N., Thu, K., \& Miyazaki, T. (2020). Dynamic modeling and validation of $a$ carbon dioxide heat pump system (Doctoral dissertation, Kyushu University). Evergreen

19) Syahrul, A. S., Normah, M. G., Oh, J. T., Robiah, A., \& Yushazaziah, M. Y. (2019). Entropy Generation Minimization of Two-Phase Flow in a Mini Channel with Genetic Algorithm. Evergreen, 6(1), 39-43.

20) Golshokouh, I., Golshokouh, M., Ani, F. N., Kianpour, E., \& Syahrullail, S. (2013). Investigation of physical properties for jatropha oil in different temperature as lubricant oil. Life Science Journal, 10(8s).

21) Syahrullail, S., Wira, J. Y., Wan Nik, W. B., \& Fawwaz, W. N. (2013). Friction characteristics of RBD palm olein using four-ball tribotester. In Applied Mechanics and materials (Vol. 315, pp. 936940). Trans Tech Publications Ltd.

22) Razak, D. M., Syahrullail, S., Sapawe, N., Azli, Y., \& Nuraliza, N. (2015). A new approach using palm olein, palm kernel oil, and palm fatty acid distillate as alternative biolubricants: improving tribology in metal-on-metal contact. Tribology Transactions, 58(3), 511-517. 